\title{
Clinical Diagnosis of Stroke Related to Brain Atrophy on Computed Tomography
}

\author{
Rasba Naeem ${ }^{*}$, Akash John ${ }^{2}$, Muhammad Ahmad Naeem ${ }^{3}$, Syed Muhammad Yousaf Farooq ${ }^{4}$, Nosheen Arshad ${ }^{5}$, \\ Muhammad Hashaam ${ }^{6}$ \\ ${ }^{1}$ Medical Imaging Doctor, Department of Radiology Sciences and Medical Imaging, The University of Lahore, Gujrat, Pakistan \\ ${ }^{2,3,5}$ Lecturer, Department of Radiology Sciences and Medical Imaging, the University of Lahore, Gujrat Pakistan \\ ${ }^{4}$ Associate Professor, Department of Allied Health Sciences, the University of Lahore, Gujrat, Pakistan
}

\section{Article History \\ Received: 13.03 .2021 \\ Accepted: 22.04 .2021}

Published: 30.04 .2021

Journal homepage:

https://www.easpublisher.com

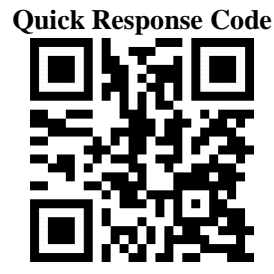

Abstract: Background: Brain Atrophy refers to the continuous loss of brain cells with the time and loss of connections between these neurons of brain tissues. Brain atrophy can be considered as the ultimate organ effect of cardiovascular risk factors. Advanced brain atrophy is described following hemorrhagic and ischemic stroke. Objective: To evaluate the frequency of brain atrophy and risk factors in stroke patients. Materials and Methods: This cross-sectional study was conducted on 150 patients having ischemic and hemorrhagic stroke between the periods of March 2020 to February 2021. The data was collected from the emergency department of Tertiary care Government hospital. The patients included were 68 males \& 82 females examined on Computed Tomography. Changes of Evans Index were taken as a marker of brain atrophy on Computed Tomography. Results: Out of 150 stroke patients, 79 patients $(49=$ males and $30=$ females) had brain atrophy with a mean age of 55.51. In Atrophic patients, 49 had hypertension, 30 had diabetes mellitus, 67 had ventriculomegaly, 39 had seizures, 42 had infarction, 66 had cognitive impairment, 18 had Depression, 66 had ischemic, and 13 had a hemorrhagic stroke. Conclusion: In conclusion, post-stroke consequences lead to brain atrophy and are also associated with various risk factors. In Ischemic stroke, brain atrophy is more prevalent than in hemorrhagic stroke.

Keywords: Brain Atrophy, Computed Tomography, Ischemic stroke, Hemorrhagic stroke, Evan's Index.

Copyright (C) 2021 The Author(s): This is an open-access article distributed under the terms of the Creative Commons Attribution 4.0 International License (CC BY-NC 4.0) which permits unrestricted use, distribution, and reproduction in any medium for non-commercial use provided the original author and source are credited.

\section{INTRODUCTION}

Stroke is the major etiology of death and a primary contributor to cognitive deficits and long-term disability [1-3]. A stroke occurs when a blood vessel is suddenly blocked by embolism or thrombus, causing almost a complete loss of oxygen and glucose to the brain tissue [4]. Deficits may include movement, thinking, memory, speech problems, and partial paralysis [5]. After a stroke, $15-30 \%$ of stroke survivors are permanently affected, and $20 \%$ need institutional care [6]. According to WHOM, due to stroke, 10.8 percent of deaths occur out of 56 million each year worldwide. Stroke can significantly deplete life quality, as measured by neurological deficiencies and cognitive function impairment [7]. The National Institutes of Health Stroke Scale is a tool for measuring the intensity of a stroke and an indicator of prognosis. Stroke is divided into two groups according to its causes, either hemorrhagic or ischemic. Hemorrhagic stroke occurs due to the accumulation of blood in the brain's parenchyma that contributes to raises local pressure and disrupting the normal anatomy. The chief risk factors of hemorrhagic stroke are hypertension, heavy alcohol consumption, and advanced age [9]. This form of stroke is a prevalent cause of permanent brain injury, with significant damage occurring during the first seven days after a stroke [10] In the United States, Intra-cerebral hemorrhage is a common fatal type of stroke that kills 30,000 individuals per year [11]. Ischemic stroke accounts for about $85 \%$, while hemorrhagic stroke accounts for about $15 \%$ of all strokes [5]. Ischemic stroke occurs due to sudden depletion or absence of blood flow to the region of the brain, causing a loss of neurological functions [8]. Patients with Ischemic stroke usually have a higher survival rate than patients with hemorrhagic stroke [2]. Post-stroke patients have a higher rate of brain atrophy [12].

Brain atrophy has been correlated to stroke risk factors, such as hypertension, smoking habits, and diabetes in epidemiological studies [13]. In survivors of stroke, cerebral atrophy is correlated with post-stroke 
dementia and may be a sign of neurodegenerative disease [14]. Computed Tomography offers the advantages of expense, speed, and reduced exclusion criteria compared to Magnetic Resonance Imaging [15]. Following a stroke and infarction, CT scan images are used to classify abnormal brain tissue [16].

This study will find out the stroke's frequency, which leads to brain atrophy in patients with either ischemic or hemorrhagic stroke. Post-stroke symptoms will reduce the chances of brain atrophy due to early diagnosis and management. This study will conclude the most prevalent type of stroke leading to brain atrophy following associated risk factors.

\section{Methods And Materials}

This study was conducted in the department of radiology in the Tertiary care government hospital. One hundred fifty patients with a history of stroke were included in this Cross-sectional study that came to the emergency department between the periods of March 2020 to February 2021. Patients between 14 to 90 years of age group were included in this study. All the patients were referred for CT brain to the Department of Radiology, between the study period and stroke history. Patients other than having stroke were excluded from the study. CT scan was performed to investigate these patients. CT brain of all the patients was performed in Toshiba Aquilion 64 slices CT scanner. Axial sections were obtained with a slice thickness of $3 \mathrm{~mm}$ from the skull base to the vertex. SPSS version 19 was used to perform data analysis. For categorical data like Age, Range, minimum, maximum, mean and standard deviation was used. For quantitative data, frequency and percentages were used.

Table-1: Descriptive Statistics of Age of patients

\begin{tabular}{|l|l|l|l|l|l|l|}
\hline & N & Range & Minimum & Maximum & Mean & Std. Deviation \\
\hline Age & 150 & 76.00 & 14.00 & 90.00 & 55.51 & 16.04 \\
\hline Valid N (listwise) & 150 & & & & & \\
\hline
\end{tabular}

Table 1 demonstrates the statistics of Age of patients. Out of 150 patients, range was 76, minimum age was 14 , maximum age was 90 , mean was 55.51 and standard deviation was 16.04. Graph chart shows the statistics of age.

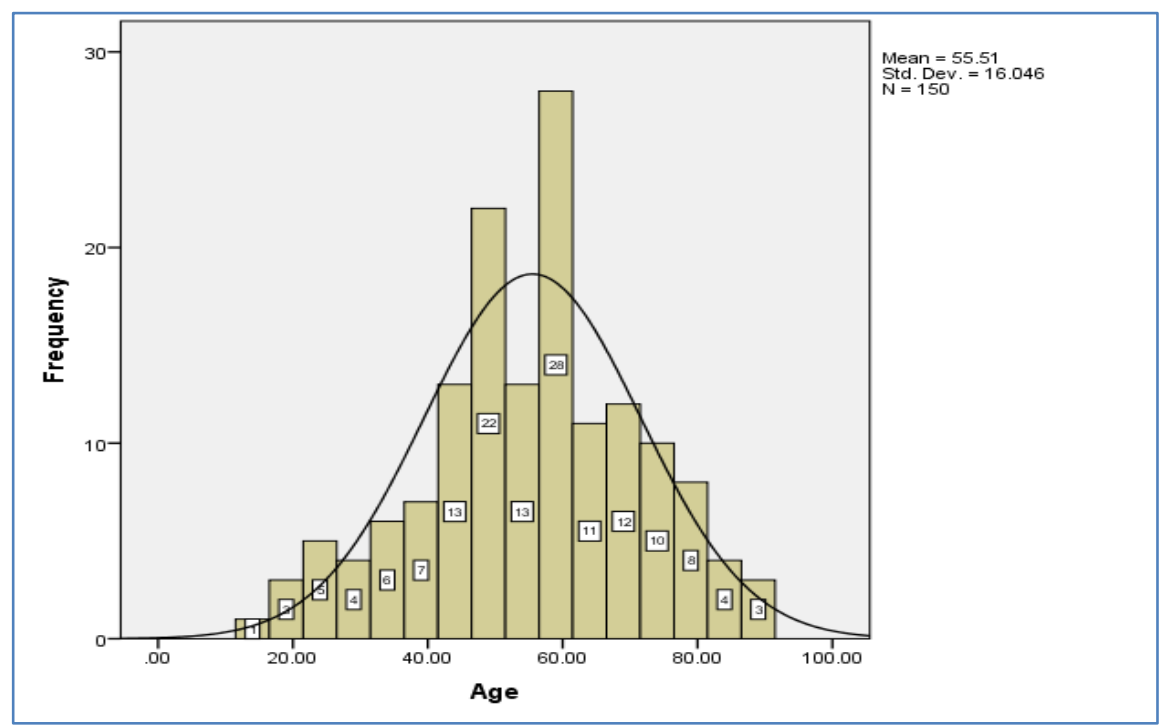

Table-2: Brain Atrophy* ischemic/hemorrhage Crosstabulation

\begin{tabular}{|c|c|c|c|c|c|}
\hline & \multicolumn{2}{|c|}{ ischemic/hemorrhage } & \multirow[t]{2}{*}{ Total } \\
\hline & & & Ischemic & $\begin{array}{l}\text { Hemorrhagi } \\
\text { c }\end{array}$ & \\
\hline \multirow{4}{*}{$\begin{array}{l}\text { Brain } \\
\text { Atrophy }\end{array}$} & \multirow[t]{2}{*}{ Yes } & Count & 66 & 13 & 79 \\
\hline & & $\%$ within Brain Atrophy & $83.5 \%$ & $16.5 \%$ & $100.0 \%$ \\
\hline & \multirow[t]{2}{*}{ N0 } & Count & 57 & 14 & 71 \\
\hline & & $\%$ within Brain Atrophy & $80.3 \%$ & $19.7 \%$ & $100.0 \%$ \\
\hline \multirow{2}{*}{\multicolumn{2}{|c|}{ Total }} & Count & 123 & 27 & 150 \\
\hline & & $\%$ within Brain Atrophy & $82.0 \%$ & $18.0 \%$ & $100.0 \%$ \\
\hline
\end{tabular}


Table-2: Shows that the ischemic stroke $(83.5 \%)$ is higher than the hemorrhagic stroke $(16.5 \%)$.

Table-3: Gender * Brain Atrophy Crosstabulation

\begin{tabular}{|c|c|c|c|c|c|}
\hline & \multicolumn{2}{|c|}{ Brain Atrophy } & \multirow[t]{2}{*}{ Total } \\
\hline & & & Yes & No & \\
\hline \multirow[t]{4}{*}{ Gender } & \multirow[t]{2}{*}{ Male } & Count & 49 & 19 & 68 \\
\hline & & $\%$ within Gender & $72.1 \%$ & $27.9 \%$ & $100.0 \%$ \\
\hline & \multirow[t]{2}{*}{ Female } & Count & 30 & 52 & 82 \\
\hline & & $\%$ within Gender & $36.6 \%$ & $63.4 \%$ & $100.0 \%$ \\
\hline \multirow{2}{*}{\multicolumn{2}{|c|}{ Total }} & Count & 79 & 71 & 150 \\
\hline & & $\%$ within Gender & $52.7 \%$ & $47.3 \%$ & $100.0 \%$ \\
\hline
\end{tabular}

Table 3 presents that the stroke was greater in females $(n=82)$ than males $(n=68)$ while brain atrophy was greater in males $(72.1 \%)$ than females $(36.6 \%)$.

Table-4: Risk Factors * Involved in brain Atrophy

\begin{tabular}{|c|c|c|c|c|c|}
\hline \multicolumn{6}{|c|}{ (a) Brain Atrophy * HTN Crosstabulation } \\
\hline & & & \multicolumn{2}{|l|}{ HTN } & \multirow[t]{2}{*}{ Total } \\
\hline & & & yes & no & \\
\hline \multirow[t]{4}{*}{ Brain Atrophy } & \multirow[t]{2}{*}{ yes } & Count & 48 & 31 & 79 \\
\hline & & $\%$ within Brain Atrophy & $60.8 \%$ & $39.2 \%$ & $100.0 \%$ \\
\hline & \multirow[t]{2}{*}{ no } & Count & 56 & 15 & 71 \\
\hline & & $\%$ within Brain Atrophy & $78.9 \%$ & $21.1 \%$ & $100.0 \%$ \\
\hline \multirow{2}{*}{\multicolumn{2}{|c|}{ Total }} & Count & 104 & 46 & 150 \\
\hline & & \% within Brain Atrophy & $69.3 \%$ & $30.7 \%$ & $100.0 \%$ \\
\hline
\end{tabular}

\begin{tabular}{|c|c|c|c|c|c|}
\hline \multicolumn{6}{|c|}{ (b) Brain Atrophy * Diabetes Crosstabulation } \\
\hline & & & \multicolumn{2}{|c|}{ Diabetes } & \multirow[t]{2}{*}{ Total } \\
\hline & & & yes & no & \\
\hline \multirow[t]{4}{*}{ Brain Atrophy } & \multirow[t]{2}{*}{ Yes } & Count & 30 & 49 & 79 \\
\hline & & $\%$ within Brain Atrophy & $38.0 \%$ & $62.0 \%$ & $100.0 \%$ \\
\hline & \multirow[t]{2}{*}{ No } & Count & 34 & 37 & 71 \\
\hline & & $\%$ within Brain Atrophy & $47.9 \%$ & $52.1 \%$ & $100.0 \%$ \\
\hline \multirow{2}{*}{\multicolumn{2}{|c|}{ Total }} & Count & 64 & 86 & 150 \\
\hline & & $\%$ within Brain Atrophy & $42.7 \%$ & $57.3 \%$ & $100.0 \%$ \\
\hline
\end{tabular}

\begin{tabular}{|c|c|c|c|c|c|}
\hline \multicolumn{6}{|c|}{ (c) Brain Atrophy * Seizures Crosstabulation } \\
\hline & & & \multicolumn{2}{|c|}{ Seizures } & \multirow[t]{2}{*}{ Total } \\
\hline & & & Yes & No & \\
\hline \multirow[t]{4}{*}{ Brain Atrophy } & \multirow[t]{2}{*}{ Yes } & Count & 39 & 40 & 79 \\
\hline & & $\%$ within Brain Atrophy & $49.4 \%$ & $50.6 \%$ & $100.0 \%$ \\
\hline & \multirow[t]{2}{*}{ No } & Count & 25 & 46 & 71 \\
\hline & & $\%$ within Brain Atrophy & $35.2 \%$ & $64.8 \%$ & $100.0 \%$ \\
\hline \multirow{2}{*}{\multicolumn{2}{|c|}{ Total }} & Count & 64 & 86 & 150 \\
\hline & & $\%$ within Brain Atrophy & $42.7 \%$ & $57.3 \%$ & $100.0 \%$ \\
\hline
\end{tabular}

\begin{tabular}{|c|c|c|c|c|c|}
\hline \multicolumn{6}{|c|}{ (d) Brain Atrophy *infarction Crosstabulation } \\
\hline & & & Yes & No & Total \\
\hline \multirow[t]{4}{*}{ Brain Atrophy } & \multirow[t]{2}{*}{ Yes } & Count & 42 & 37 & 79 \\
\hline & & $\%$ within Brain Atrophy & $53.2 \%$ & $46.8 \%$ & $100.0 \%$ \\
\hline & \multirow[t]{2}{*}{ No } & Count & 35 & 36 & 71 \\
\hline & & $\%$ within Brain Atrophy & $49.3 \%$ & $50.7 \%$ & $100.0 \%$ \\
\hline \multirow{2}{*}{\multicolumn{2}{|c|}{ Total }} & Count & 77 & 73 & 150 \\
\hline & & $\%$ within Brain Atrophy & $51.3 \%$ & $48.7 \%$ & $100.0 \%$ \\
\hline
\end{tabular}




\begin{tabular}{|c|c|c|c|c|c|}
\hline \multicolumn{6}{|c|}{ (e) Brain Atrophy * Depression Crosstabulation } \\
\hline & & & \multicolumn{2}{|c|}{ Depression } & \multirow[t]{2}{*}{ Total } \\
\hline & & & yes & no & \\
\hline \multirow[t]{4}{*}{ Brain Atrophy } & \multirow{2}{*}{$\begin{array}{l}\mathrm{Ye} \\
\mathrm{s}\end{array}$} & Count & 18 & 61 & 79 \\
\hline & & $\%$ within Brain Atrophy & $22.8 \%$ & $77.2 \%$ & $100.0 \%$ \\
\hline & \multirow[t]{2}{*}{ No } & Count & 9 & 62 & 71 \\
\hline & & \% within Brain Atrophy & $12.7 \%$ & $87.3 \%$ & $100.0 \%$ \\
\hline \multirow{2}{*}{\multicolumn{2}{|c|}{ Total }} & Count & 27 & 123 & 150 \\
\hline & & $\%$ within Brain Atrophy & $18.0 \%$ & $82.0 \%$ & $100.0 \%$ \\
\hline
\end{tabular}

\begin{tabular}{|c|c|c|c|c|c|}
\hline \multicolumn{6}{|c|}{ (f) Brain Atrophy * cognitive impairment Crosstabulation } \\
\hline & & & \multicolumn{2}{|c|}{ cognitive impairment } & \multirow{2}{*}{ Total } \\
\hline & & & Yes & no & \\
\hline \multirow{4}{*}{ Brain Atrophy } & \multirow{2}{*}{ yes } & Count & 66 & 13 & 79 \\
\hline & & $\%$ within Brain Atrophy & $83.5 \%$ & $16.5 \%$ & $100.0 \%$ \\
\hline & \multirow[t]{2}{*}{ no } & Count & 43 & 28 & 71 \\
\hline & & $\%$ within Brain Atrophy & $60.6 \%$ & $39.4 \%$ & $100.0 \%$ \\
\hline \multirow{2}{*}{\multicolumn{2}{|c|}{ Total }} & Count & 109 & 41 & 150 \\
\hline & & $\%$ within Brain Atrophy & $72.7 \%$ & $27.3 \%$ & $100.0 \%$ \\
\hline
\end{tabular}

\begin{tabular}{|c|c|c|c|c|c|}
\hline \multicolumn{6}{|c|}{ (g) Brain Atrophy * ventriculomegaly Crosstabulation } \\
\hline & & & \multicolumn{2}{|c|}{ ventriculomegaly } & \multirow[t]{2}{*}{ Total } \\
\hline & & & Yes & No & \\
\hline \multirow{4}{*}{ Brain Atrophy } & \multirow{2}{*}{ Yes } & Count & 67 & 12 & 79 \\
\hline & & \% within Brain Atrophy & $84.8 \%$ & $15.2 \%$ & $100.0 \%$ \\
\hline & \multirow[t]{2}{*}{ No } & Count & 35 & 36 & 71 \\
\hline & & $\%$ within Brain Atrophy & $49.3 \%$ & $50.7 \%$ & $100.0 \%$ \\
\hline \multirow{2}{*}{\multicolumn{2}{|c|}{ Total }} & Count & 102 & 48 & 150 \\
\hline & & $\%$ within Brain Atrophy & $68.0 \%$ & $32.0 \%$ & $100.0 \%$ \\
\hline
\end{tabular}

Table 4 demonstrated that the risk factors like (a) hypertension (61\%), (b) Diabetes Mellitus (38\%), (c) Seizures (49\%), (d) Infarction (53\%),(e) Depression (23\%), (f) Cognitive Impairment (84\%) and (g) Ventriculomegaly $(85 \%)$ involved in brain atrophic patients.

\section{RESUltS}

150 patients with the clinical diagnosis of stroke were examined on Computed Tomography. All patients had complete baseline clinical data, history, and imaging data. In 150 stroke patients, 68 were males, and 82 were females. 79 patients had brain atrophy with a mean age of 57.73 (median $=58, \mathrm{SD}=16.46$, range $=$ 76 , minimum $=14$ and maximum $=90$ ), which included 49 males and 30 females. In the patient's group with brain atrophy, 49 had hypertension, 30 had diabetes mellitus, 67 had ventriculomegaly, 39 had seizures, 42 had infarction, 66 had cognitive impairment, and 18 had Depression. In atrophic patients, 66 had ischemic, and 13 had a hemorrhagic stroke in history.

\section{DISCUSSION}

This study evaluate the brain atrophy in a group of patients with stroke and assessing either type of stroke (ischemic or hemorrhagic) causes shrinkage of the brain. The researcher confirmed that changes in these patients by linear measurements of ventricular size were performed serially on CT scans. Table 3 showed that an increasing number of males 49 compared to females 30 had brain atrophy in our study. Jiang $\mathrm{Xu}$ demonstrated more brain atrophy with aging in male subjects, $7.22 \%$, than in female subjects $3.03 \%$ [17].

Our research in Table 2 showed that the patients with ischemic stroke $(n=66)$ consequently cause higher brain atrophy rates than hemorrhagic stroke. This higher rate of atrophy may indicate tissue damage at a subclinical stage, bringing these people at greater risk of cognitive impairment. $\mathrm{R} \mathrm{J}$ Lwalters reported a higher $0.39 \%$ atrophy rate in the transient ischemic attack group. Transient ischemic Attack can also be associated with subclinical cerebrovascular disorder and elevated rates of cerebral atrophy, which may lead to cognitive dysfunction and dementia [18]. Arani Nitkunan concluded that patients with Small vessel disease $(-0.914 \% \pm 0.8 \%)$ and control subjects $(0.498 \% \pm 0.4 \%)$ [19]. We have shown in Table 4 (a) that hypertension is correlated to brain atrophy following a Stroke. There are several theories as to why high blood pressure is linked to elevated rates of cerebral atrophy. It has the potential to cause neuronal malfunction and death. Secondly, it may be part of events that leads to cerebrovascular disease, which causes brain atrophy. The hippocampal neuronal loss in patients with vascular dementia caused by 
microvascular pathology is important. There is increasing evidence of hypertensive patients with cerebrovascular disease, and across our 79 atrophic patients, hypertension showed in 49 patients. The current research supports the view that proper treatment of risk factors (especially hypertension) for cerebrovascular disease is necessary after a stroke. S.G.C. Van Eldren reported that people with diabetes had amplified brain atrophy ( $\mathrm{p}<0.01)$ compared to the control candidates [20]. Muhammad Munir documented that patients with diabetes $(n=11)$ demonstrated significantly higher levels of brain atrophy than those without $(n=3)$ [21]. Our research documented that 30 patients with diabetes mellitus had brain atrophy. G. Fein documented that the cognitive impairment associated with atrophy of the cortical gray matter and hippocampus [22]. Erkan Sari reported that for many years Evans Index had been used in diagnostic imaging. Evans index is used to measure enlargement of ventricular dilation that occurs due to brain atrophy. The increase in ventricle size compensates for brain atrophy, but the EI is still less than 0.3 [23].

\section{CONCLUSION}

In conclusion, there is an association between brain atrophy and clinical outcomes after stroke. Poststroke consequences lead to brain atrophy and are also associated with various risk factors like hypertension, debates mellitus, ventriculomegaly, and infarction, seizures, depression and cognitive impairment. Brain atrophy is more frequent in ischemic stroke as compared to hemorrhagic stroke.

\section{Ethical Consideration}

While conducting the study, the ethical committee of the University of Lahore will set the rules, regulations and respect the interests of the research participants.

\section{Confidentiality of Patients}

A written informed consent was taken from all the patients. All collected data will be kept confidential for research purpose only.

\section{Financial Support}

No financial support

\section{Confllict of Interest}

in this research

We declared that there is no conflict of study

\section{REFRENCES}

1. Khedr, E. M., Hamed, S. A., El-Shereef, H. K., Shawky, O. A., Mohamed, K. A., Awad, E. M., ... \& Eltahtawy, M. A. (2009). Cognitive impairment after cerebrovascular stroke: Relationship to vascular risk factors. Neuropsychiatric Disease and Treatment, 5, 103.
2. Kalaria, R. N., Akinyemi, R., \& Ihara, M. (2016). Stroke injury, cognitive impairment and vascular dementia. Biochimica et Biophysica Acta (BBA)Molecular Basis of Disease, 1862(5), 915-925.

3. Lo, E. H., Dalkara, T., \& Moskowitz, M. A. (2003). Mechanisms, challenges and opportunities in stroke. Nature reviews neuroscience, 4(5), 399-414.

4. Muir, K. W., Tyrrell, P., Sattar, N., \& Warburton, E. (2007). Inflammation and ischaemic stroke. Current opinion in neurology, 20(3), 334342.

5. Lakhan, S. E., Kirchgessner, A., \& Hofer, M. (2009). Inflammatory mechanisms in ischemic stroke: therapeutic approaches. Journal of translational medicine, 7(1), 1-11.

6. Association, A.H. (2003). Heart disease and stroke statistics. from. http://www americanheart org/downloadable/heart/10590179711482003HDS StatsBookREV7-03.

7. De Haan, R. J., Limburg, M., Van der Meulen, J. H. P., Jacobs, H. M., \& Aaronson, N. K. (1995). Quality of life after stroke: impact of stroke type and lesion location. Stroke, 26(3), 402-408.

8. Scherbakov, N., Von Haehling, S., Anker, S. D., Dirnagl, U., \& Doehner, W. (2013). Stroke induced Sarcopenia: muscle wasting and disability after stroke. International journal of cardiology, 170(2), 89-94.

9. Qureshi, A. I., Mendelow, A. D., \& Hanley, D. F. (2009). Intracerebral haemorrhage. The Lancet, 373(9675), 1632-1644.

10. Robinson, S. R., Dang, T. N., Dringen, R., \& Bishop, G. M. (2009). Hemin toxicity: a preventable source of brain damage following hemorrhagic stroke. Redox Report, 14(6), 228-235.

11. Aronowski, J., \& Zhao, X. (2011). Molecular pathophysiology of cerebral hemorrhage: secondary brain injury. Stroke, 42(6), 1781-1786.

12. Brodtmann, A., Khlif, M. S., Egorova, N., Veldsman, M., Bird, L. J., \& Werden, E. (2020). Dynamic regional brain atrophy rates in the first year after ischemic stroke. Stroke, 51(9), e183e192.

13. Longstreth Jr, W. T., Arnold, A. M., Manolio, T. A., Burke, G. L., Bryan, N., Jungreis, C. A., ... \& Fried, L. (2000). Clinical correlates of ventricular and sulcal size on cranial magnetic resonance imaging of 3,301 elderly people. Neuroepidemiology, 19(1), 30-42.

14. Pasquier, F., Leys, D., Weerts, J. G., MounierVehier, F., Barkhof, F., \& Scheltens, P. (1996). Inter-and intraobserver reproducibility of cerebral atrophy assessment on MRI scans with hemispheric infarcts. European neurology, 36(5), 268-272.

15. Rorden, C., Bonilha, L., Fridriksson, J., Bender, B., \& Karnath, H. O. (2012). Age-specific CT and MRI templates for spatial normalization. Neuroimage, 61(4), 957-965.

16. Gillebert, C. R., Humphreys, G. W., \& Mantini, D. (2014). Automated delineation of stroke lesions 
using brain CT images. NeuroImage: Clinical, 4, $540-548$

17. Xu, J., Kobayashi, S., Yamaguchi, S., Iijima, K. I., Okada, K., \& Yamashita, K. (2000). Gender effects on age-related changes in brain structure. American journal of neuroradiology, 21(1), 112-118.

18. Walters, R. J. L., Fox, N. C., Schott, J. M., Crum, W. R., Stevens, J. M., Rossor, M. N., \& Thomas, D. J. (2003). Transient ischaemic attacks are associated with increased rates of global cerebral atrophy. Journal of Neurology, Neurosurgery \& Psychiatry, 74(2), 213-216.

19. Nitkunan, A., Lanfranconi, S., Charlton, R. A., Barrick, T. R., \& Markus, H. S. (2011). Brain atrophy and cerebral small vessel disease: a prospective follow-up study. Stroke, 42(1), 133138.

20. Van Elderen, S. G. C., De Roos, A., De Craen, A. J. M., Westendorp, R. G. J., Blauw, G. J., Jukema, J.
W., ... \& Van Der Grond, J. (2010). Progression of brain atrophy and cognitive decline in diabetes mellitus: a 3-year follow-up. Neurology, 75(11), 997-1002.

21. Munir, M., Ursenbach, J., Reid, M., Gupta Sah, R., Wang, M., Sitaram, A., ... \& Alzheimer's Disease Neuroimaging Initiative. (2019). Longitudinal brain atrophy rates in transient ischemic attack and minor ischemic stroke patients and cognitive profiles. Frontiers in neurology, 10, 18.

22. Fein, G., Di Sclafani, V., Tanabe, J., Cardenas, V., Weiner, M. W., Jagust, W. J., ... \& Chui, H. (2000). Hippocampal and cortical atrophy predict dementia in subcortical ischemic vascular disease. Neurology, 55(11), 1626-1635.

23. Sar1, E., Sarı, S., Akgün, V., Özcan, E., İnce, S., Babacan, O., ... \& Yeşilkaya, E. (2015). Measures of ventricles and evans' index: from neonate to adolescent. Pediatric neurosurgery, 50(1), 12-17.

Cite This Article: Rasba Naeem et al (2021). Clinical Diagnosis of Stroke Related to Brain Atrophy on Computed Tomography. EAS J Radiol Imaging Technol, 3(2), 107-112. 